\title{
Musculature adaption in patients with lumbosacral transitional vertebrae: a matched-pair analysis of 46 patients
}

\author{
Luis Becker ${ }^{1} \cdot$ Katharina Ziegeler ${ }^{2} \cdot$ Torsten Diekhoff $^{2} \cdot$ Yannick Palmowski $^{1} \cdot$ Matthias Pumberger $^{1}$. \\ Friederike Schömig ${ }^{1}$
}

Received: 23 November 2020 / Revised: 20 January 2021 / Accepted: 20 January 2021 / Published online: 3 February 2021

(C) The Author(s) 2021

\begin{abstract}
Objective Even though lumbosacral transitional vertebrae (LSTV) are one of the most common congenital anomalies of the spine, their effect on surrounding soft tissues is not well-studied. We therefore aimed at analyzing the association between LSTV and changes in volume, mass, symmetry, and degeneration of lumbar and trunk muscles.

Materials and methods Abdomen-pelvis CT scans were analyzed in patients with LSTV and a matched control group. LSTV were classified according to the Castellvi classification. Muscles were segmented from the remaining soft tissue and their cross-sectional area and volume were examined at five defined levels. Threshold segmentation was used to differentiate between muscle fibers and fat tissue. Matched pairs were compared using Wilcoxon rank sum tests. For comparison of categorical data, chi-squared tests were performed and for associations between the degree of fusion and muscle size and degeneration, Spearman's correlation coefficients were calculated. Inter- and intrarater reliabilities were evaluated by computing intraclass correlation coefficients.

Results Forty-six patients with LSTV and 46 controls were included. Muscle volume of the paraspinal and trunk muscles was significantly lower $\left(707.0 \mathrm{~cm}^{3}\right.$ vs. $\left.809.7 \mathrm{~cm}^{3}, p<0.001\right)$ and fatty muscle changes were significantly increased in all but the caudal paravertebral muscles of LSTV patients (M. psoas $p<0.04$, M. quadratus lumborum $p<0.001$, paravertebral muscles $p=$ 0.011 , M. rectus abdominis $p<0.001$, M. obliquus abdominis $p<0.001$ ). Correlations between the degree of Castellvi classification and muscle volume were significant $(p=0.001)$.

Conclusion LSTV are associated with a reduction in muscle volume and an increase in muscle degeneration of both lumbar and trunk muscles.
\end{abstract}

Keywords Transitional $\cdot$ Adaptation $\cdot$ Atrophy $\cdot$ Asymmetry

Matthias Pumberger

matthias.pumberger@charite.de

Luis Becker

luis-alexander.becker@charite.de

Katharina Ziegeler

katharina.ziegeler@ charite.de

Torsten Diekhoff

torsten.diekhoff@charite.de

Yannick Palmowski

yannick.palmowski@charite.de

Friederike Schömig

friederike.schoemig@charite.de

1 Center for Musculoskeletal Surgery, Charité - University Medicine Berlin, Charitéplatz 1, 10117 Berlin, Germany

2 Department of Radiology, Charité - University Medicine Berlin, Berlin, Germany

\section{Introduction}

Lumbosacral transitional vertebrae (LSTV) are one of the most common congenital anomalies of the spine, with a reported prevalence of 4-36\%, and are defined as either a sacralization of the lowest lumbar segment or a lumbarization of the superior sacral segment [1,2]. Castellvi et al. introduced a radiographic classification system for LSTV in 1984, defining four different types of LSTV: Type I includes unilateral (Ia) or bilateral (Ib) dysplastic transverse processes; type II is an incomplete unilateral (IIa) or bilateral (IIb) lumbarization or sacralization with an enlarged transverse process with a diarthrodial joint between itself and the sacrum; type III is a unilateral (IIIa) or bilateral (IIIb) lumbarization or sacralization with complete osseous fusion of the transverse process to the sacrum; and type IV is defined as a unilateral type II transition with a type III transition on the contralateral side [3]. Diagnosis of LSTV classically includes lateral and 
Ferguson radiographs but characterization of LSTV is best performed by computed tomography (CT) [1].

Despite some controversies in the literature, there appears to be an association between LSTV and the occurrence of low back pain (LBP) caused by various etiologies, such as disc or spinal canal pathology at the level above transition, degeneration of the anomalous articulation, facet joint arthrosis, and stenosis secondary to a broadened transverse process [1]. However, other studies reported no correlation between LBP and LSTV and no increased incidence of structural pathologies in patients with LSTV $[4,5]$.

Core trunk and low back muscle atrophy has been shown to be associated with LBP and, with less strong evidence, with degenerative disc disease and spinal stenosis [6-9]. As the posterior muscles of the lumbar spine provide stability to the lumbar vertebral segments and control movement of the lumbar spine, muscular integrity plays an important role in the maintenance of global spinal alignment [10, 11]. Previous studies have shown that atrophy of paraspinal muscles may lead to altered thoracic kyphosis, lumbar lordosis, and sacralvertebral angles both in adults with and without degenerative spinal disease [12-14]. Due to this important role trunk and lumbar muscles play in spinal integrity and pain development, physiotherapy has been shown to significantly improve functionality and positively alter the course of LBP [15].

To determine whether the occurrence of LSTV is associated with changes in the psoas muscle, quadratus lumborum muscle, rectus abdominis muscle, abdominal oblique muscle, and paraspinal muscles, we analyzed muscle volume, mass, symmetry, and degeneration at five defined levels of CT scans of patients with and without LSTV using the image processing software Amira.

\section{Materials and methods}

\section{Patients and ethics approval}

A retrospective matched-pair analysis of the abdomen-pelvis CT scans was performed. The study was approved by the local ethics board (ethics proposal number EA1/300/19). Included patients underwent abdomen-pelvis CT scans in our department of radiology from 2016 to 2019. The CT scans were high-resolution abdomen-pelvis CT images with an image section at least from level L1 to the greater trochanter and were acquired due to reasons other than LBP. Exclusion criteria were metastatic and primary malignancy of the musculoskeletal system, previous spinal or pelvic fusion surgery, incomplete image data, and insufficient image quality for software evaluation. Eight-hundred nineteen patients were included. Fifty-two patients had LSTV, six of which had to be excluded due to insufficient image quality. The resulting 46 patients were matched with control patients from the cohort described above, using propensity score matching with a tolerance of 0.01 , matching for age, gender, weight category, and indication for $\mathrm{CT}$.

\section{Image acquisition and radiographic classification}

Images were taken by an 80 -row or a 320 -row CT scanner (Canon Aquillon Prime and Canon Aquillon One Vision, Canon Medical Systems, Otawara, Japan). The chosen isometric slice thickness was $1.0 \mathrm{~mm}$ in a medium soft tissue core. CT images were reconstructed with the image visualization and analysis software Amira for Life \& Biomedical Sciences certified by the Food and Drug Administration (Thermo Fisher Scientific Materials \& Structural Analysis c/ o Zuse-Institut Berlin, Germany). Image analysis, muscle segmentation, and measurements were performed by a spine surgeon with experience in measuring radiological spinal parameters, who was trained by a spinal-attending surgeon. LSTV were classified by a radiological resident with specialized training in musculoskeletal radiology (5 years of experience in clinical musculoskeletal imaging and research). A random sample of 50 patients of the original study cohort was additionally classified by an experienced board-certified musculoskeletal radiologist and scored a second time by the primary reader to calculate inter- and intrareader reliabilities.

In each patient, LSTV were classified according to the Castellvi classification for both the left and the right side as shown in Fig. 1. We then divided all vertebral sides into the following groups: no transition (I), enlarged transverse process (II), pseudarticulation of the transverse process with the sacral bone (III), and fusion of the transverse process with the sacrum (IV).
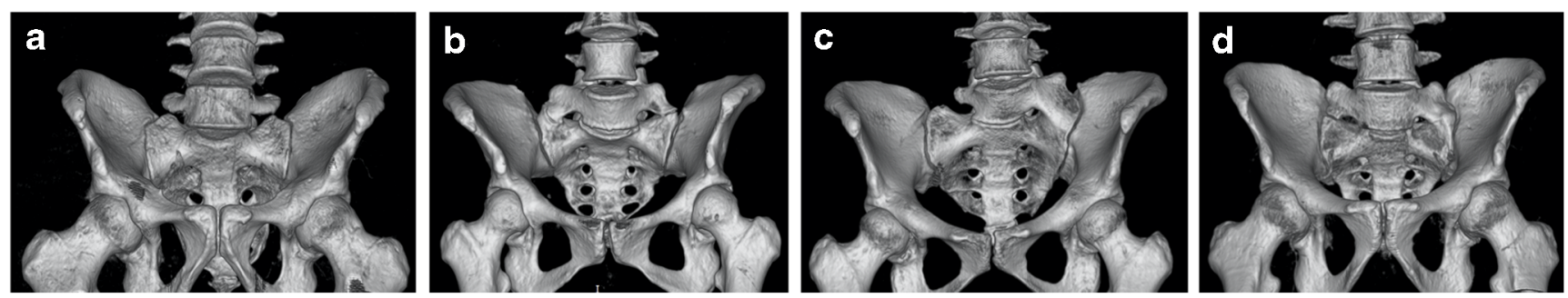

Fig. 1 CT scans of different LSTV types in our patient population. a. Castellvi Ib, b. Castellvi IIb, c. Castellvi IIIa, d. Castellvi IV. CT= computed tomography, LSTV = lumbosacral transitional vertebrae 


\section{Muscle segmentation and measurement}

For image analysis, we used the image processing software Amira. We segmented the muscles from the remaining soft tissue by semi-automated procedures using threshold segmentation tools and manual muscle contouring. We examined muscle cross-sectional area and the muscle volume of the psoas muscle, quadratus lumborum muscle, and paraspinal muscles (erector spinae, multifidus). To verify the accuracy of the measurements, 24 of the 92 patients were remeasured. Twelve patients were randomly selected from both the cohorts of patients with and without LSTV. We differentiated between muscle fibers and fat tissue by using threshold segmentation and assessed the mean muscle density as well as the proportion between muscle mass and fat as signs of muscle degeneration [16]. We determined the muscles' cross-sectional area in axial sectional imaging at five defined levels. For standardization of our measurements, we determined each measuring level at the center of the anterior edge of the intervertebral disc between the two vertebrae. The uppermost measurement level was between the first and second vertebra below the ribbearing vertebrae. The other measurement levels were between the second and third, third and fourth, fourth and fifth, and fifth and sixth vertebrae as shown in Fig. 2. Muscle degeneration as expressed by visual fat content was assessed using a classification adapted to the Goutallier grading (Fig. 3): grade 0 shows no fatty infiltration, grade 1 some fatty streaks, grade 2 less than $50 \%$ fat, grade $350 \%$ fat, and grade 4 more than $50 \%$ fat [16-18].

\section{Data analysis}

All statistical analyses were performed using SPSS Version 25 (IBM Corporation, New York, USA). Controls were identified from the same study cohort using propensity score matching with a tolerance of 0.01 , matching for age, gender, weight category, and indication for CT. The Wilcoxon rank sum test for the comparison of paired samples was used due to the study design as a matched pair analysis. Categorical data were compared using chi-squared test. The associations between the degree of fusion (none, enlarged transverse process, pseudoarticulation, fusion) and muscle size and degeneration were investigated using Spearman's correlation coefficients. Intra-class correlation coefficients (ICCs) were calculated for inter- and intrareader reliabilities using a two-way mixed model. A significance level of $p<0.05$ was assumed for all tests.

\section{Results}

\section{Patients}

A total of 46 patients with transitional vertebrae matched with 46 controls. As per study design, LSTV patients did not differ from their matched controls regarding median age (51.5, interquartile range, IQR 37.0-68.0, vs. 50.0, IQR 31.0-70.0; $p=0.872)$, proportion of female patients $(23 / 46$ vs. $19 / 46$; $p=0.236)$ or proportion of normal weight patients (29/46 vs. $25 / 46 ; p=0.585)$. CT scans were acquired with query of malignancy (27/46 vs. 25/46), infection (11/46 vs. 20/46),
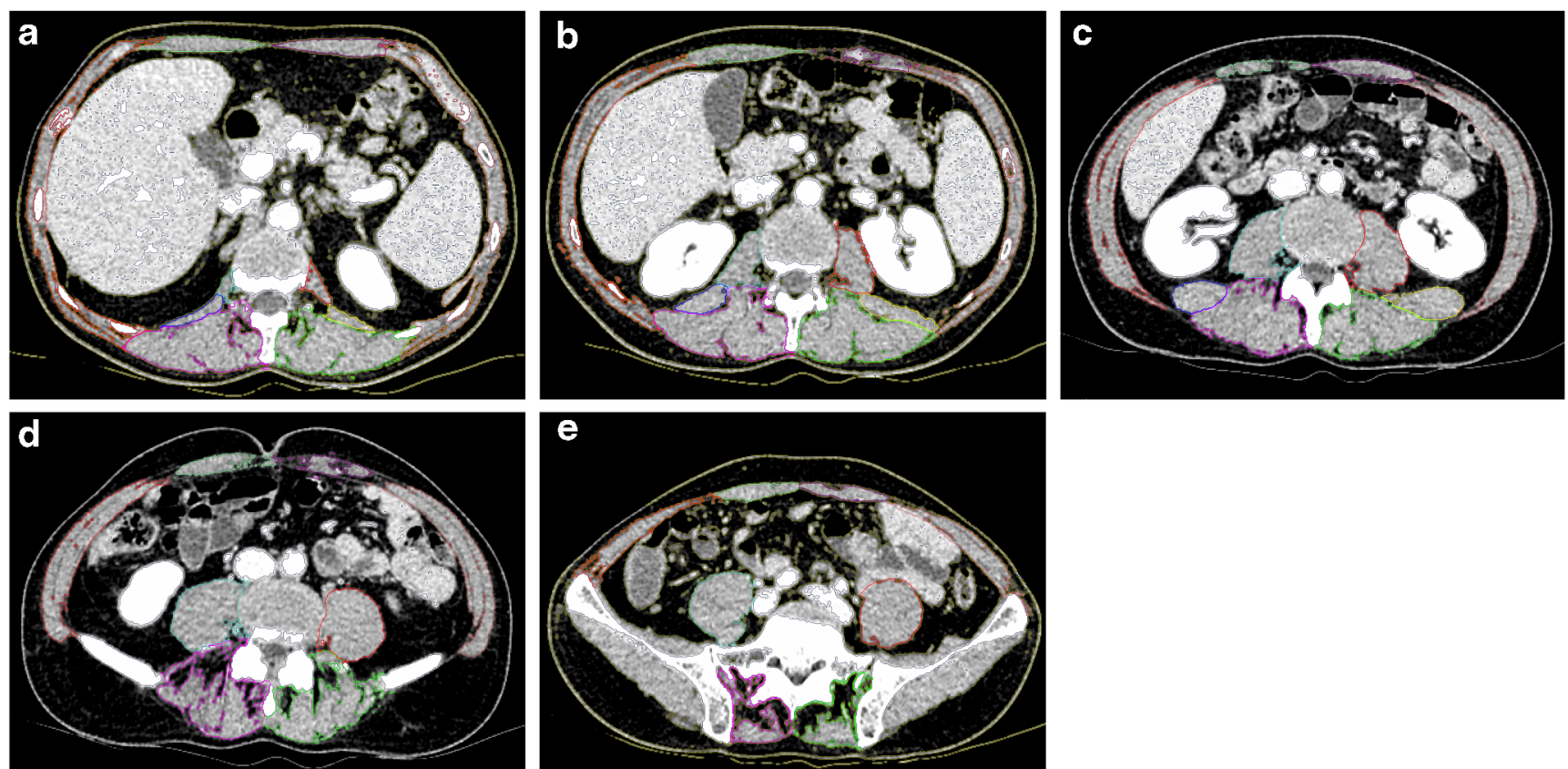

Fig. 2 Measurements of the psoas, paraspinal, rectus abdominis, and obliquus abdominis muscles at five levels and the quadratus lumborum muscle at three levels in a patient with Castellvi type IIb. 2a. Level L1/2, 2b. level L2/3, 2c. level L3/4, 2d. level L4/5, 2e. level L5/S1 

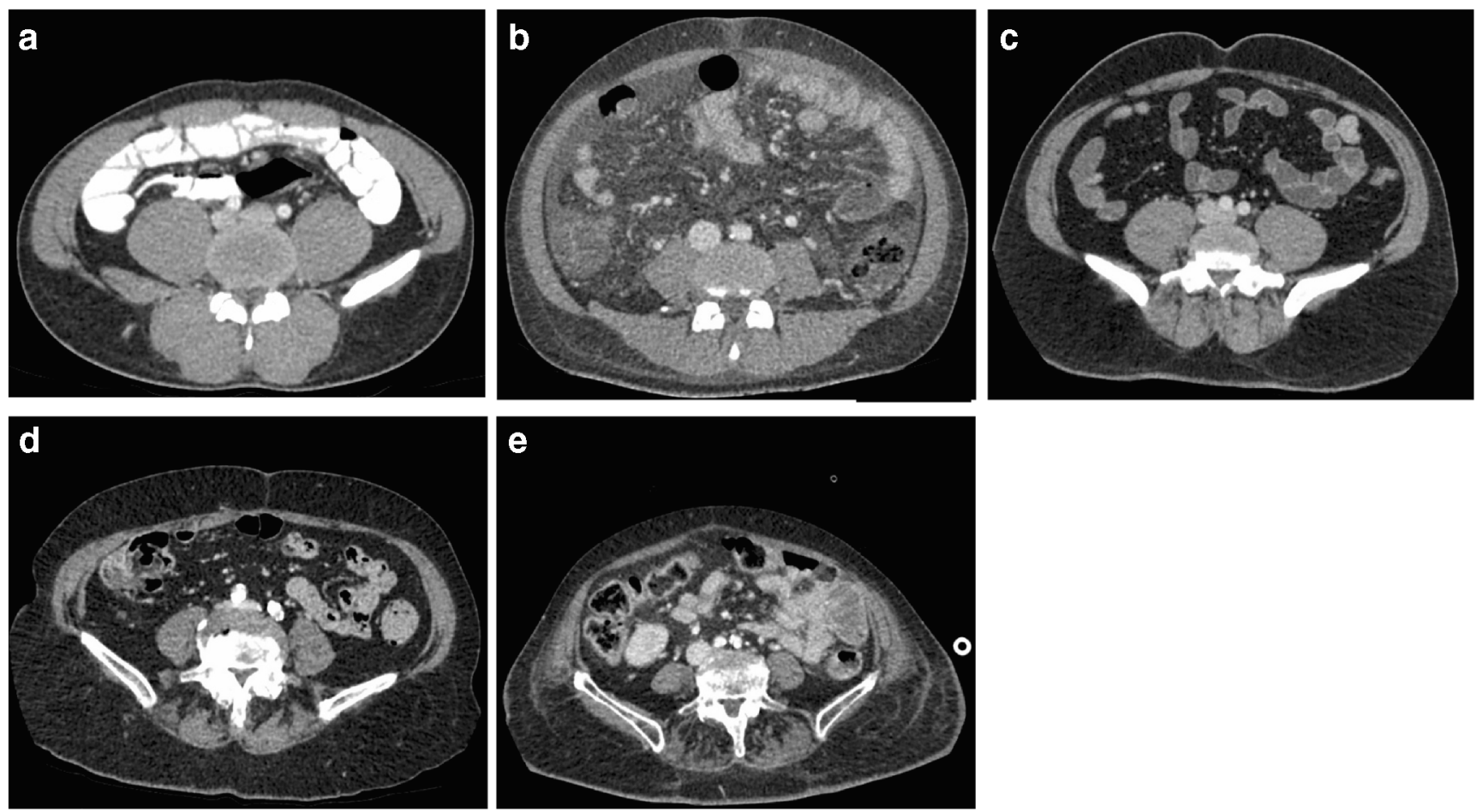

Fig. 3 CT scans showing different Goutallier gradings of the paravertebral muscles at level L4/5. a. Grade 0: no fatty infiltration. b. Grade 1: some fatty streaks. c. Grade 2: less than 50\% fatty infiltration. d. Grade 3: 50\% infiltration. e. Grade 4: more than 50\% fatty infiltration

bleeding (2/46 vs. $0 / 46)$ or other (7/46 vs. $6 / 46)$ - the distribution did not differ significantly between groups $(p=0.126)$. Frequencies of Castellvi grades are shown in Table 1. For classification of LSTV, interreader reliability was good with ICCs of 0.832 (95\%CI $0.705-0.904)$ for the right and 0.712 (95\%CI $0.493-0.836)$ for the left side. Intrareader reliability was very good with ICCs of 0.958 (95\%CI $0.925-0.976)$ for the right and 0.905 (95\% CI $0.833-0.946)$ for the left side.

\section{Muscle - volume}

For muscle volume measurements, the intrareader reliability was very good with an ICC of 0.995 (95\%CI 0.994-0.996). Total muscle volume was calculated by adding the volumes of all individual muscles of one side. We found a statistically significant $(p<0.001)$ lower total muscle volume for patients with LSTV (mean $707.0 \mathrm{~cm}^{3}$, IQR $632.9 \mathrm{~cm}^{3}-1006.4 \mathrm{~cm}^{3}$ ) in relation to our control group (mean $809.7 \mathrm{~cm}^{3}$, IQR $689.9 \mathrm{~cm}^{3}-1035.5 \mathrm{~cm}^{3}$ ). Similar findings were found for total muscle volume for M. psoas $(p=0.028)$, paraspinal musculature $(p<0.001)$, M. rectus abdominis $(p<0.001)$, and M.

Table 1 Frequencies of Castellvi grades

\begin{tabular}{lllll}
\hline Type & I & II & III & IV \\
\hline$n(\%)$ & $14(30.4 \%)$ & $22(47.8 \%)$ & $6(13.0 \%)$ & $4(8.7 \%)$ \\
\hline
\end{tabular}

obliquus abdominis $(p<0.001)$. No differences were seen in total muscle volume for M. quadratus lumborum. The crosssectional area of the individual muscles examined at the five levels is shown in Table 2. An example of muscular atrophy in an LSTV patient is presented in Fig. 4.

\section{Muscle — symmetry}

Asymmetry of muscle mass, defined as the median difference in the cross-sectional area between the left and right side at different levels, did not differ significantly in single levels or in total muscle volume between patients with asymmetrical LSTV (Castellvi Ia, IIa and IIIa; $n=31)$ and controls $(n=31)$.

\section{Goutallier grading and density}

We found significantly more fatty muscle changes for all analyzed muscles in patients with LSTV (M. psoas $p<0.04$, M. quadratus lumborum $p<0.001$, paravertebral muscles $p=$ 0.011 , M. rectus abdominis $p<0.001$, M. obliquus abdominis $p<0.001$ ). Patients with LSTV showed more fatty degeneration at every examined level except the paravertebral muscles at $L 2 / 3$ and $L 4 / 5$. Table 3 summarizes the grading by presenting frequencies of modified Goutallier grades. Quantitative analysis of radiodensity as a parameter for fatty degeneration of the muscle as whole did not reveal significant differences between both groups. 
Table 2 Muscle cross-sectional area in $\mathrm{cm}^{2}$ at the five measured levels as well as the muscle volume in $\mathrm{cm}^{3}$. Significant values are marked in bold

\begin{tabular}{|c|c|c|c|c|c|c|c|c|c|c|}
\hline & \multicolumn{2}{|l|}{ M. psoas } & \multicolumn{2}{|c|}{ M. quad. lumborum } & \multicolumn{2}{|c|}{ Paraspinal m. } & \multicolumn{2}{|c|}{ M. rect. abd. } & \multicolumn{2}{|c|}{ M. obliquus abd. } \\
\hline & LSTV & Control & LSTV & Control & LSTV & Control & LSTV & Control & LSTV & Control \\
\hline $\mathrm{L} 1 / 2$ & $\begin{array}{c}3.15 \\
p=0.457\end{array}$ & 2.72 & $\begin{array}{l}2.96 \\
p=0.635\end{array}$ & 3.01 & $\begin{array}{c}21.86 \\
p=0.015\end{array}$ & 22.90 & $\begin{array}{c}5.25 \\
p=0.005\end{array}$ & 5.55 & $\begin{array}{c}23.75 \\
p=0.027\end{array}$ & 24.81 \\
\hline $\mathrm{L} 2 / 3$ & $\begin{array}{c}6.56 \\
p=0.309\end{array}$ & 6.87 & $\begin{array}{l}4.01 \\
p=0.717\end{array}$ & 4.05 & $\begin{array}{c}22.17 \\
p=0.001\end{array}$ & 23.19 & $\begin{array}{c}5.07 \\
p=0.082\end{array}$ & 5.26 & $\begin{array}{c}23.37 \\
p=0.019\end{array}$ & 24.69 \\
\hline $\mathrm{L} 3 / 4$ & $\begin{array}{c}10.21 \\
p=0.058\end{array}$ & 10.28 & $\begin{array}{l}5.12 \\
p=0.163\end{array}$ & 4.93 & $\begin{array}{c}21.40 \\
p=0.003\end{array}$ & 22.42 & $\begin{array}{c}5.47 \\
p=0.003\end{array}$ & 5.89 & $\begin{array}{c}23.36 \\
p=0.003\end{array}$ & 24.89 \\
\hline $\mathrm{L} 4 / 5$ & $\begin{array}{c}11.79 \\
p=0.006\end{array}$ & 12.24 & - & - & $\begin{array}{c}16.96 \\
p<0.001\end{array}$ & 18.96 & $\begin{array}{c}5.50 \\
p=0.014\end{array}$ & 5.81 & $\begin{array}{c}17.51 \\
p<0.001\end{array}$ & 19.83 \\
\hline $\mathrm{L} 5 / \mathrm{S} 1$ & $\begin{array}{c}9.21 \\
p=0.256\end{array}$ & 9.33 & - & - & $\begin{array}{c}8.14 \\
p<0.001\end{array}$ & 10.07 & $\begin{array}{c}5.61 \\
p=0.004\end{array}$ & 6.29 & $\begin{array}{c}8.55 \\
p=0.027\end{array}$ & 9.59 \\
\hline Volume & $\begin{array}{l}121.57 \\
\mathrm{p}=0.028\end{array}$ & 124.95 & $\begin{array}{l}26.63 \\
p=0.217\end{array}$ & 27.25 & $\begin{array}{l}278.99 \\
p<0.001\end{array}$ & 292.07 & $\begin{array}{l}78.81 \\
p=0.001\end{array}$ & 82.26 & $\begin{array}{l}274.68 \\
p<0.001\end{array}$ & 298.63 \\
\hline
\end{tabular}

\section{Muscle mass and degeneration pending on the degree of expression of LSTV}

We found weak but significant negative correlations between the degree of fusion and muscle cross-sectional area for paraspinal muscles $(r=-0.230 ; p=0.001)$, M. rectus abdominis $(r=-0.211 ; p=0.002)$ and $\mathrm{M}$. obliquus abdominis $(r=-0.2541 ; p<0.001)$. In terms of overall muscle volume, we found a significant negative correlation between volume and degree of fusion $(r=-0.227 ; p=0.001)$. Our results show a weak but significant negative correlation between the degree of expression of LSTV and fatty degeneration of M. psoas $(r=-0.221 ; p=0.003)$, M. quadratus lumborum $(r=-0.381$; $p<0.001)$, paraspinal muscles $(r=-0.320 ; p<0.001)$, M. rectus abdominis $(r=-0.320 ; p<0.001)$, and M. obliquus abdominis $(r=-0.252 ; p=0.001)$.

\section{Discussion}

Our results show a significant reduction of total muscle volume in patients with LSTV compared with our control group $\left(707.0 \mathrm{~cm}^{3}\right.$ vs. $\left.809.7 \mathrm{~cm}^{3}, p<0.001\right)$ as well as a significant reduction of muscle volumes of the paraspinal musculature, M. rectus abdominis, and $\mathrm{M}$. obliquus abdominis. Furthermore, we found significantly more fatty muscle changes in the M. psoas $(p<0.04)$, M. quadratus lumborum $(p<0.001)$, paravertebral muscles $(p=0.011)$, M. rectus abdominis $(p<0.001)$, and M. obliquus abdominis $(p<0.001)$ in patients with LSTV.

As changes in lumbar muscles have been shown to not only affect global sagittal alignment of the spine but also contribute to the development of LBP, we performed this retrospective study to analyze whether there is an association between the occurrence of LSTV and changes in muscle volume, mass, and degeneration. Multiple studies have analyzed the correlation between LSTV and LBP, but evidence on the exact mechanisms of pain development is still lacking.

In patients with LSTV, we found total muscle volume to be significantly reduced. Additionally, paraspinal muscles, psoas muscle as well as both the M. rectus abdominis and M. obliquus abdominis showed significantly lower muscle masses compared to the control group. This reduction of muscle volume and mass in LSTV patients may be caused by
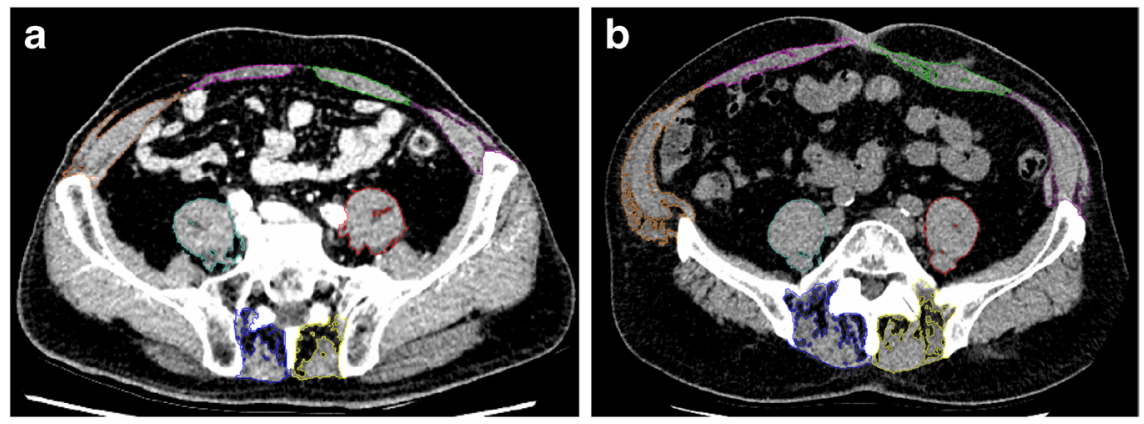

C

M. psoas

Paraspinal m.

Rectus abd.

Obliquus abd.
$\operatorname{LSTV}\left[\mathrm{cm}^{2}\right]$ Control $\left[\mathrm{cm}^{2}\right]$

$23.4 \quad 35.6$

$13.3 \quad 38.5$

$8.3 \quad 22.7$

$19.0 \quad 46.8$

Fig. 4 Measurements of the cross-sectional area of the psoas, paraspinal, rectus abdominis and obliquus abdominis muscles at level 5 in a patient with an LSTV Castellvi type IIIb (a.) and in a patient without an LSTV (b.). c. shows the resulting cross-sectional areas 
Table 3 Frequencies of modified Goutallier grades per level. $P$ values are derived from chi-square test. Significant values are marked in bold

\begin{tabular}{|c|c|c|c|c|c|c|c|c|c|c|}
\hline & & LSTV $(r$ & & & & Controls & 46) & & & $\mathrm{p}$ \\
\hline Modifi & routallier & I & II & III & IV & I & II & III & IV & \\
\hline $\mathrm{L} 1 / 2$ & M. psoas & $89.13 \%$ & $10.87 \%$ & $0.00 \%$ & $0.00 \%$ & $73.91 \%$ & $4.35 \%$ & $0.00 \%$ & $0.00 \%$ & $<0.001$ \\
\hline & M. quad. lumb. & $95.65 \%$ & $4.35 \%$ & $0.00 \%$ & $0.00 \%$ & $70.65 \%$ & $5.43 \%$ & $0.00 \%$ & $0.00 \%$ & $<0.001$ \\
\hline & Paraspinal m. & $47.83 \%$ & $52.17 \%$ & $0.00 \%$ & $0.00 \%$ & $60.87 \%$ & $31.52 \%$ & $1.09 \%$ & $0.00 \%$ & 0.004 \\
\hline & M. rectus abd. & $61.96 \%$ & $31.52 \%$ & $6.52 \%$ & $0.00 \%$ & $54.35 \%$ & $21.74 \%$ & $2.17 \%$ & $1.09 \%$ & $<0.001$ \\
\hline & M. obliquus abd. & $9.78 \%$ & $88.04 \%$ & $2.17 \%$ & $0.00 \%$ & $35.87 \%$ & $61.96 \%$ & $2.17 \%$ & $0.00 \%$ & $<0.001$ \\
\hline $\mathrm{L} 2 / 3$ & M. psoas & $89.13 \%$ & $10.87 \%$ & $0.00 \%$ & $0.00 \%$ & $71.74 \%$ & $8.70 \%$ & $0.00 \%$ & $0.00 \%$ & $<0.001$ \\
\hline & M. quad. lumb. & $86.96 \%$ & $11.96 \%$ & $1.09 \%$ & $0.00 \%$ & $78.26 \%$ & $2.17 \%$ & $0.00 \%$ & $0.00 \%$ & $<0.001$ \\
\hline & Paraspinal m. & $48.91 \%$ & $51.09 \%$ & $0.00 \%$ & $0.00 \%$ & $46.74 \%$ & $46.74 \%$ & $2.17 \%$ & $0.00 \%$ & 0.101 \\
\hline & M. rectus abd. & $51.09 \%$ & $48.91 \%$ & $0.00 \%$ & $0.00 \%$ & $50.00 \%$ & $31.52 \%$ & $0.00 \%$ & $2.17 \%$ & $<0.001$ \\
\hline & M. obliquus abd. & $15.22 \%$ & $84.78 \%$ & $0.00 \%$ & $0.00 \%$ & $30.43 \%$ & $69.57 \%$ & $0.00 \%$ & $0.00 \%$ & 0.014 \\
\hline $\mathrm{L} 3 / 4$ & M. psoas & $92.39 \%$ & $7.61 \%$ & $0.00 \%$ & $0.00 \%$ & $80.43 \%$ & $1.09 \%$ & $0.00 \%$ & $0.00 \%$ & $<0.001$ \\
\hline & M. quad. lumb. & $83.70 \%$ & $13.04 \%$ & $3.26 \%$ & $0.00 \%$ & $72.83 \%$ & $3.26 \%$ & $0.00 \%$ & $0.00 \%$ & $<0.001$ \\
\hline & Paraspinal m. & $26.09 \%$ & $70.65 \%$ & $3.26 \%$ & $0.00 \%$ & $42.39 \%$ & $51.09 \%$ & $3.26 \%$ & $0.00 \%$ & 0.024 \\
\hline & M. rectus abd. & $58.70 \%$ & $40.22 \%$ & $1.09 \%$ & $0.00 \%$ & $57.61 \%$ & $16.30 \%$ & $1.09 \%$ & $4.35 \%$ & $<0.001$ \\
\hline & M. obliquus abd. & $20.65 \%$ & $79.35 \%$ & $0.00 \%$ & $0.00 \%$ & $56.52 \%$ & $40.22 \%$ & $1.09 \%$ & $0.00 \%$ & $<0.001$ \\
\hline $\mathrm{L} 4 / 5$ & M. psoas & $90.22 \%$ & $9.78 \%$ & $0.00 \%$ & $0.00 \%$ & $89.13 \%$ & $4.35 \%$ & $0.00 \%$ & $0.00 \%$ & 0.019 \\
\hline & Paraspinal m. & $5.43 \%$ & $70.65 \%$ & $23.91 \%$ & $0.00 \%$ & $8.70 \%$ & $61.96 \%$ & $21.74 \%$ & $2.17 \%$ & 0.124 \\
\hline & M. rectus abd. & $54.35 \%$ & $45.65 \%$ & $0.00 \%$ & $0.00 \%$ & $59.78 \%$ & $27.17 \%$ & $0.00 \%$ & $2.17 \%$ & 0.001 \\
\hline & M. obliquus abd. & $18.48 \%$ & $81.52 \%$ & $0.00 \%$ & $0.00 \%$ & $43.48 \%$ & $56.52 \%$ & $0.00 \%$ & $0.00 \%$ & $<0.001$ \\
\hline $\mathrm{L} 5 / \mathrm{S} 1$ & M. psoas & $91.30 \%$ & $8.70 \%$ & $0.00 \%$ & $0.00 \%$ & $93.48 \%$ & $2.17 \%$ & $0.00 \%$ & $0.00 \%$ & 0.022 \\
\hline & Paraspinal m. & $0.00 \%$ & $85.87 \%$ & $9.78 \%$ & $4.35 \%$ & $2.17 \%$ & $59.78 \%$ & $35.87 \%$ & $1.09 \%$ & $<0.001$ \\
\hline & M. rectus abd. & $59.78 \%$ & $36.96 \%$ & $3.26 \%$ & $0.00 \%$ & $73.91 \%$ & $10.87 \%$ & $0.00 \%$ & $1.09 \%$ & $<0.001$ \\
\hline & M. obliquus abd. & $22.83 \%$ & $77.17 \%$ & $0.00 \%$ & $0.00 \%$ & $45.65 \%$ & $54.35 \%$ & $0.00 \%$ & $0.00 \%$ & 0.001 \\
\hline
\end{tabular}

restrictions in mobility and a higher degree of connection through osseous fusion [8]. A possible explanation for this may be that biomechanical changes caused by LSTV affect paravertebral muscles as well as abdominal muscles. LSTV therefore is not only a change in bony structure of the spine but may also cause changes in soft tissue anatomy. To the authors' knowledge, this is the first study showing that with increasingly pronounced disturbances of the lumbo-sacral transition, a significant decrease in the muscle volume of paraspinal and trunk muscles occurs.

Furthermore, we show significantly greater total muscle degeneration of all analyzed muscles in LSTV patients compared to the control group. As mentioned above, morphological changes in LSTV patients lead to altered anatomy and biomechanics with limitation of motion at the same level and hypermobility above the LSTV level [19-21]. This hypermobility of adjacent segments may cause stress on muscular structures, which in turn may lead to increased muscle degeneration. As it has been previously shown that excessive muscular stress caused by decreased muscular activity or repetitive injuries may cause fat infiltration, correct training of stabilizing muscles of the spine may reduce this degenerative process
$[16,22,23]$. Regarding the increased fatty infiltration shown in LSTV patients, this may be of particular importance in preventing early muscular degeneration.

Our results also confirm the findings of Bahadir and Ulger [24] showing that an asymmetrical degree of severity of an LSTV does not lead to significant muscular asymmetry. However, patients with LSTV showed significantly less degeneration of the caudal paraspinal muscles and more degeneration of the psoas muscle and the quadratus lumborum muscle. This suggests that patients with LSTV have a different muscular load than patients without LSTV.

As both a reduction in muscle volume and an increase in muscle degeneration may play a role in the pathogenesis of LBP in LSTV patients, preventive strategies against pain development need to be established. There is increasing evidence that in LBP patients, exercise alone or exercise in combination with education programs can reduce the risk of a future episode of LBP as well as future LBP intensity $[25,26]$. Additionally, a recent study showed that early physiotherapy significantly improves functionality and reduces pain in patients with chronic LBP [15], highlighting the importance of physiotherapy in the initial treatment of LBP. As our results show 
changes in volume and degeneration of lumbar and trunk musculature of LSTV patients, which may be caused by or may cause the development of LBP, exercise and physiotherapy need to be considered important strategies in pain prevention. In addition to training autochthonous back muscles, which had a lower volume in patients with LSTV than in the control group, strengthening of the psoas and quadratus lumborum muscles as well as abdominal muscles should be investigated as preventive strategies in LSTV patients.

Some limitations have to be discussed. Due to insufficient data, we excluded six patients, which may have caused an unclear bias. However, as to our knowledge, this still is the largest analysis of CT scans of LSTV patients we are confident the presented data is robust. Due to the retrospective setting, we were not able to include clinical findings such as the occurrence of LBP in our analysis and thus were not able to differentiate between asymptomatic and symptomatic patients. Therefore, we were not able to establish a causal relationship between muscle changes and LBP development in LSTV patients. Additionally, morphological and degenerative changes especially in the facet or disc were not investigated but may play a role in muscle changes and degeneration.

Our results provide evidence that LSTV lead to a reduction of total muscle volume as well as a reduction of muscle volumes of the M. rectus abdominis, M. obliquus abdominis, and paraspinal muscles, all of which showed a significant negative correlation with the degree of fusion. Moreover, we found increased muscle degeneration of all analyzed lumbar and trunk muscles in patients with LSTV, which may be caused by the previously shown limitation of motion at the same level and hypermobility above the LSTV level. To evaluate the impact these changes have on the development of LBP in LSTV patients, further studies including clinical findings such as patient symptoms need to be performed.

Funding Open Access funding enabled and organized by Projekt DEAL. This research did not receive any specific grant from funding agencies in the public, commercial, or not-for-profit sectors.

\section{Declarations}

Conflict of interest The authors declare no competing interests.

Ethics approval and consent to participate All procedures performed in studies involving human participants were in accordance with the ethical standards of the institutional and/or national research committee and with the 1964 Helsinki declaration and its later amendments or comparable ethical standards. The study was approved by the local ethics board (ethics proposal number EA1/300/19).
Financial disclosure This research did not receive any specific grant from funding agencies in the public, commercial, or not-for-profit sectors.

Open Access This article is licensed under a Creative Commons Attribution 4.0 International License, which permits use, sharing, adaptation, distribution and reproduction in any medium or format, as long as you give appropriate credit to the original author(s) and the source, provide a link to the Creative Commons licence, and indicate if changes were made. The images or other third party material in this article are included in the article's Creative Commons licence, unless indicated otherwise in a credit line to the material. If material is not included in the article's Creative Commons licence and your intended use is not permitted by statutory regulation or exceeds the permitted use, you will need to obtain permission directly from the copyright holder. To view a copy of this licence, visit http://creativecommons.org/licenses/by/4.0/.

\section{References}

1. Konin GP, Walz DM. Lumbosacral transitional vertebrae: classification, imaging findings, and clinical relevance. AJNR Am J Neuroradiol. 2010;31(10):1778-86.

2. Matson DM, Maccormick LM, Sembrano JN, Polly DW. Sacral dysmorphism and lumbosacral transitional vertebrae (LSTV) review. Int J Spine Surg. 2020;14(Suppl 1):14-9.

3. Castellvi AE, Goldstein LA, Chan DP. Lumbosacral transitional vertebrae and their relationship with lumbar extradural defects. Spine (Phila Pa 1976). 1984;9(5):493-5.

4. Tini PG, Wieser C, Zinn WM. The transitional vertebra of the lumbosacral spine: its radiological classification, incidence, prevalence, and clinical significance. Rheumatol Rehabil. 1977;16(3): $180-5$.

5. Elster AD. Bertolotti's syndrome revisited. Transitional vertebrae of the lumbar spine. Spine (Phila Pa 1976). 1989;14(12):1373-7.

6. Kalichman L, Carmeli E, Been E. The association between imaging parameters of the paraspinal muscles, spinal degeneration, and low back pain. Biomed Res Int. 2017;2017:2562957.

7. Belavý DL, Armbrecht G, Richardson CA, Felsenberg D, Hides JA. Muscle atrophy and changes in spinal morphology: is the lumbar spine vulnerable after prolonged bed-rest? Spine (Phila Pa 1976). 2011;36(2):137-45.

8. Beneck GJ, Kulig K. Multifidus atrophy is localized and bilateral in active persons with chronic unilateral low back pain. Arch Phys Med Rehabil. 2012;93(2):300-6.

9. Haddas R, Samocha Y, Yang J. Effects of volitional spine stabilization on trunk control during asymmetric lifting task in patients with recurrent low back pain. Global Spine J. 2020;10(8):1006-14.

10. Ward SR, Kim CW, Eng CM, Gottschalk LJ, Tomiya A, Garfin SR, et al. Architectural analysis and intraoperative measurements demonstrate the unique design of the multifidus muscle for lumbar spine stability. J Bone Joint Surg Am. 2009;91(1):176-85.

11. Bogduk N, Macintosh JE, Pearcy MJ. A universal model of the lumbar back muscles in the upright position. Spine (Phila $\mathrm{Pa}$ 1976). 1992;17(8):897-913.

12. Bok DH, Kim J, Kim TH. Comparison of MRI-defined back muscles volume between patients with ankylosing spondylitis and control patients with chronic back pain: age and spinopelvic alignment matched study. Eur Spine J. 2017;26(2):528-37.

13. Masaki M, Ikezoe T, Fukumoto Y, Minami S, Tsukagoshi R, Sakuma K, et al. Association of sagittal spinal alignment with thickness and echo intensity of lumbar back muscles in middle-aged and elderly women. Arch Gerontol Geriatr. 2015;61(2):197-201. 
14. Jun HS, Kim JH, Ahn JH, Chang IB, Song JH, Kim TH, et al. The effect of lumbar spinal muscle on spinal sagittal alignment: evaluating muscle quantity and quality. Neurosurgery. 2016;79(6):847-55.

15. Martin S, Tallian K, Nguyen VT, van Dyke J, Sikand H. Does early physical therapy intervention reduce opioid burden and improve functionality in the management of chronic lower back pain? Ment Health Clin. 2020;10(4):215-21.

16. Lee SH, Park SW, Kim YB, Nam TK, Lee YS. The fatty degeneration of lumbar paraspinal muscles on computed tomography scan according to age and disc level. Spine J. 2017;17(1):81-7.

17. Battaglia PJ, Maeda Y, Welk A, Hough B, Kettner N. Reliability of the Goutallier classification in quantifying muscle fatty degeneration in the lumbar multifidus using magnetic resonance imaging. $\mathrm{J}$ Manip Physiol Ther. 2014;37(3):190-7.

18. Goutallier D, Postel JM, Bernageau J, Lavau L, Voisin MC. Fatty muscle degeneration in cuff ruptures. Pre- and postoperative evaluation by CT scan. Clin Orthop Relat Res. 1994;304:78-83.

19. Zhang B, Wang L, Wang H, Guo Q, Lu X, Chen D. Lumbosacral transitional vertebra: possible role in the pathogenesis of adolescent lumbar disc herniation. World Neurosurg. 2017;107:983-9.

20. Aihara T, Takahashi K, Ogasawara A, Itadera E, Ono Y, Moriya H. Intervertebral disc degeneration associated with lumbosacral transitional vertebrae: a clinical and anatomical study. J Bone Joint Surg (Br). 2005;87(5):687-91.
21. Luoma K, Vehmas T, Raininko R, Luukkonen R, Riihimäki H. Lumbosacral transitional vertebra: relation to disc degeneration and low back pain. Spine (Phila Pa 1976). 2004;29(2):200-5.

22. O'Sullivan PB, Dankaerts W, Burnett AF, Farrell GT, Jefford E, Naylor CS, et al. Effect of different upright sitting postures on spinal-pelvic curvature and trunk muscle activation in a pain-free population. Spine (Phila Pa 1976). 2006;31(19):E707-12.

23. Pezolato A, de Vasconcelos EE, Defino HL, Nogueira-Barbosa MH. Fat infiltration in the lumbar multifidus and erector spinae muscles in subjects with sway-back posture. Eur Spine J. 2012;21(11):2158-64.

24. Bahadir Ulger FE, Illeez OG. The effect of lumbosacral transitional vertebrae (LSTV) on paraspinal muscle volume in patients with low back pain. Acad Radiol. 2020;27(7):944-50.

25. de Campos TF, Maher CG, Fuller JT, Steffens D, Attwell S, Hancock MJ. Prevention strategies to reduce future impact of low back pain: a systematic review and meta-analysis. Br J Sports Med. 2020. https://doi.org/10.1136/bjsports-2019-101436.

26. Steffens D, Maher CG, Pereira LS, Stevens ML, Oliveira VC, Chapple M, et al. Prevention of low back pain: a systematic review and meta-analysis. JAMA Intern Med. 2016;176(2):199-208.

Publisher's note Springer Nature remains neutral with regard to jurisdictional claims in published maps and institutional affiliations. 